\title{
Study on refine and morphology change of AlFeSi phase in A380 alloy by $\mathrm{K}$ addition
}

\author{
Meng Wang ${ }^{1 *}$ \\ ${ }^{1}$ School of Mechanical and Electrical Engineering, Shenzhen Polytechnic, Shenzhen 518055 China
}

\begin{abstract}
Aluminum-Silicon (Al-Si) alloys are one of the most widely used aluminum alloys. But iron can severely deteriorate the mechanical property of Al-Si diecasting alloy because its presence leads to the precipitation of different AlFeSi intermetallic phases which damage the ductility of alloys. Thus controlling the fraction and morphology of AlFeSi phase, especially the $\beta$-AlFeSi phase is important way to refine the ductility of Al-Si die casting alloys. In this article, $\mathrm{K}$ element was added into A380 alloys to study the effect of $\mathrm{K}$ on the morphology change of AlFeSi phase. The results show that a certain level of K addition 0.05-0.1 $\mathrm{wt} \%$ will refine $\beta$-AlFeSi and transform $\beta$-AlFeSi phase to $\alpha$-AlFeSi. In addition, $\mathrm{K}$ addition can better refine $\mathrm{AlFeSi}$ at high ccoling rates. The mechanism of refinement of $\mathrm{K}$ on AlFeSi phase is analyzed.
\end{abstract}

\section{Introduction}

A380 aluminum alloy is one of the most widely used aluminum-silicon diecasting alloys. It can be used as electronic and equipment, automotive and aircraft components, and transportation parts.

In most $\mathrm{Al}-\mathrm{Si}$ die casting aluminum alloys, $\mathrm{Fe}$ is a necessary but detrimental element. With iron, die soldering can be inhibited, while the introduced brittle AlFeSi phase will also degrade mechanical properties, especially the ductility of aluminum-silicon alloys. The presence of iron leads to the precipitation of many ironcontaining intermetallic phases in the form of long, sharp angled platelets or needles, resulting in the stress concentration. These intermetallic phases severely degrade the tensile strength and ductility of the alloys. Moreover, they may affect castability by preventing the interdendritic feeding and lead to porosity by forming at the eutectic stage. It is essential to control the content and morphology of Fe-containing intermetallics in current aluminum silicon die casting research.

Among all the Fe-rich phases, two phases are most prominent. $\beta$-AlFeSi is more deleterious because of its platelet or needle-like morphologies, which are brittle and generally lead to stress concentration on needle point to impair the toughness of $\mathrm{Al}-\mathrm{Si}$ die casting alloys. Comparably, $\alpha$-AlFeSi has 3-D developed compact morphologies such as Chinese script, star-like or polygon, which is less harmful to the mechanical property of alloy. [1-3] Thus, many efforts have been devoted to refine the morphologies of $\beta$-AlFeSi or transform $\beta$-AlFeSi to $\alpha$ AlFeSi.
Therefore, some methods have been adopted to reduce the negative effect of Al-Fe-Si intermetallics, including element alloying, cooling rate control and heat treatment and other physical methods. Among these methods, element alloying is the easiest and the most common one to achieve and many studies have been conducted. [3] Mn has similar atomic lattice with $\mathrm{Fe}$ and it can substitute $\mathrm{Fe}$ in $\beta$-AlFeSi and form $\alpha-\mathrm{Al}(\mathrm{Mn}, \mathrm{Fe}) \mathrm{Si}$. Therefore, it can effectively reduce the amount of detrimental effect of $\beta$ AlFeSi. However, $\mathrm{Mn}$ can also form primary $\alpha$ $\mathrm{Al}(\mathrm{Mn}, \mathrm{Fe}) \mathrm{Si}$ sludge in $\mathrm{Al}-\mathrm{Si}$ casting alloy. $\mathrm{Sr}$ is also a good Fe substitute, while the cost and sintering problems cannot be avoid. $[1,4]$ Other elements, such as $\mathrm{Co}, \mathrm{Cr}$ and $\mathrm{Ca}$, do not have high efficiency or the cost is too high for industry application.

Potassium also acts as an effective Fe-corrector by refining the AlFeSi phase and the eutectic silicon, leading to an improvement of the strength and the ductility of the alloys, especially the elongation. The addition of the element of Potassium, $\mathrm{K}$, can both transform and refine $\beta$ $\mathrm{AlFeSi}$ at high cooling rates. $\mathrm{K}$ can also modify the eutectic Si [5]

However, there is no systematical study on the effect of $\mathrm{K}$ on Fe-containing phase of A380 alloys. So in this article, the effect of $\mathrm{K}$ content and cooling rates on $\mathrm{AlFeSi}$ phase of A380 alloy are studied. And the reason why $\mathrm{AlFeSi}$ phase can be refined by $\mathrm{K}$ is explained.

\section{Experimental}

The A380-K alloys were prepared by using A380 aluminum alloy in unmodified form supplied by ALCOA (compositions in Table 1). About $180 \mathrm{~g}$ A380 alloy was

*Corresponding author's e-mail: wangmeng04@szpt.edu.cn 
remelt in the Kerl furnace. The casting of A380 with 0.1, $0.5,1,2,3$ percent $\mathrm{K}$ in the form of Al-K master alloy has been added, holding at $710{ }^{\circ} \mathrm{C}$ for 2 hours and casting at $650{ }^{\circ} \mathrm{C}$. The molten alloy was then poured into:

(a) a steel mold, inner dimension $3 \times 1 \times 1$ inch, which was expected to resemble cooling rates close to those slow permanent mold casting $\left(3-5^{\circ} \mathrm{C} \cdot \mathrm{s}^{1}\right)$;

(b) a copper mold, inner diameter $\Phi 1 \times 1$ inch, and placed in a tank with water. $\left(\sim 20^{\circ} \mathrm{C}\right)$. The cooling rates can be closed to the ones from fast permanent mould casting $10-20{ }^{\circ} \mathrm{C} \cdot \mathrm{s}^{-1}$

(c) cold water directly. This process of melt quenching is to produce fine structure with secondary dendrite arms 6-8 $\mu \mathrm{m}$, resembling those obtained from a die-casting process.

Samples for metallographic observation were prepared with standard procedure (mounted into standard samples, grinding and polishing) and etched by $0.5 \% \mathrm{HF}$ solution. Metallographic observation has been made by the combination of optical microscopy (optical microscopy (OM, Leca) and SE image from scanning electron microscopy (FEI XL 40) with using an energy dispersive $\mathrm{X}$-ray spectroscopy. ImageJ and Photoshop software has been used to determine the influence of $\mathrm{K}$ content and cooling rate on the microstructure of A380 alloy. Particle size and shape was characterized with statistics software. The 380-xK phase diagram and cooling-curves are calculated with Thermal-Calc ${ }^{\mathrm{TM}}$ softwares.

\section{$3 \quad$ Results and discussion}

Figure 1, the Al-Si-Cu-xK phase diagram, shows that $\mathrm{K}$ element does not have effect on the formation on $\mathrm{AlFeSi}$ phase.

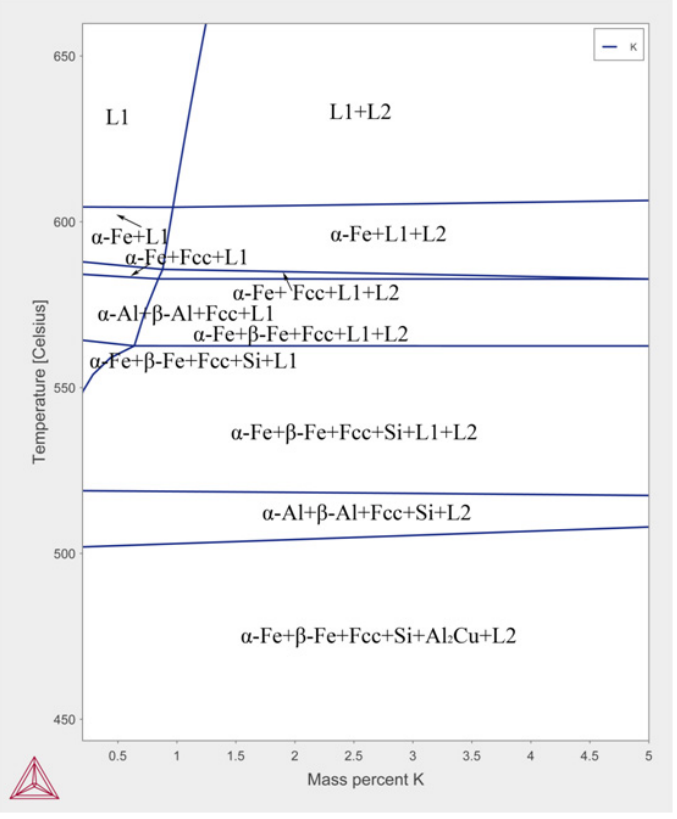

Figure 1. Al-Si-Cu-xK phase diagram

$(\mathrm{Si}=9 \%, \mathrm{Cu}=3.5 \%, \mathrm{Mn}=0.4 \%, \mathrm{Fe}=1 \%, \mathrm{Mg}=0.2 \%, \mathrm{Zn}=0.35 \%$, $\mathrm{Al}=$ bal.)

From Figure 2-4. we can see that the addition of $\mathrm{K}$ effectively reduces the size of $\beta$-AlFeSi phase and its transfer into $\alpha$-compound. With addition of $K$, the following phenomena were observed: 1) High cooling rates can eliminate $\beta$-AlFeSi phase. If the cooling rates go up to $20^{\circ} \mathrm{C} / \mathrm{s}$, no obvious $\beta$-AlFeSi can be found (Figure. 4) and only $\alpha$-AlFeSi can be seen. (Table 2-5); 2) the size of the $\alpha$-AlFeSi phase reduced with $\mathrm{K}$ addition. Compared with Figure 2 a) and d) and Figure 4 a) and d), we can see that the secondary dendrite arm spacing of 380 alloys is reduced significantly with $\mathrm{K}$ addition; 3 ) even with a lower cooling rate, $\mathrm{K}$ can effectively refine the $\beta$-AlFeSi phase. For the $5^{\circ} \mathrm{C} / \mathrm{s}$ cooling rate sample (Figure 2), with $0.5 \mathrm{~K}$ addition (Figure $2 \mathrm{~b}$ ), $\beta$-AlFeSi phase fraction goes down to $0.41 \%$ (Table 3 ) and no $\beta$-AlFeSi phase can be detected if the $\mathrm{K}$ content goes up to $2 \%$ (Figure $2 \mathrm{~d}$ and Table 4). If the cooling rates are increased to $10^{\circ} \mathrm{C} / \mathrm{s}$, no $\beta$-AlFeSi phase can be seen with $1 \% \mathrm{~K}$ addition (Figure $3 \mathrm{c}$ and Table 5); 4) addition of $\mathrm{K}$ does not introduce sludge under any cooling rates. It should be an ideal Fe modifier.
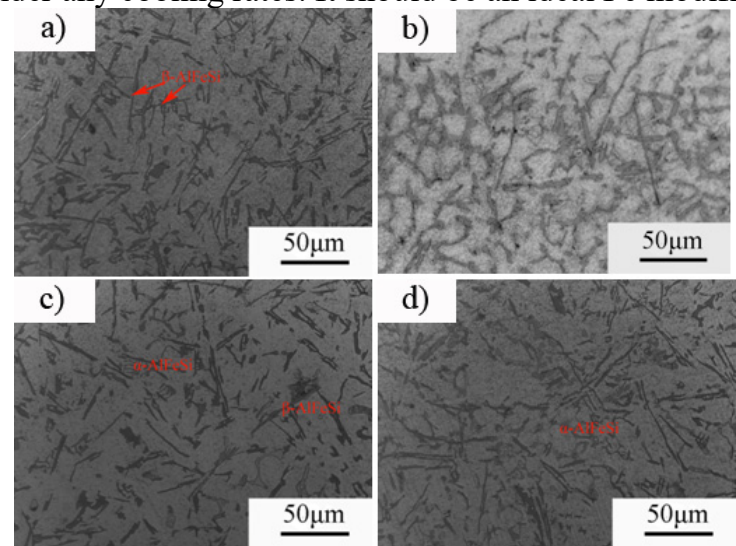

Figure 2. Microstructure of A380 alloy with different $\mathrm{K}$ addition at $5{ }^{\circ} \mathrm{C} / \mathrm{s}$

0.1 ; (b) 0.5 ; (c) 1 ; (d)2
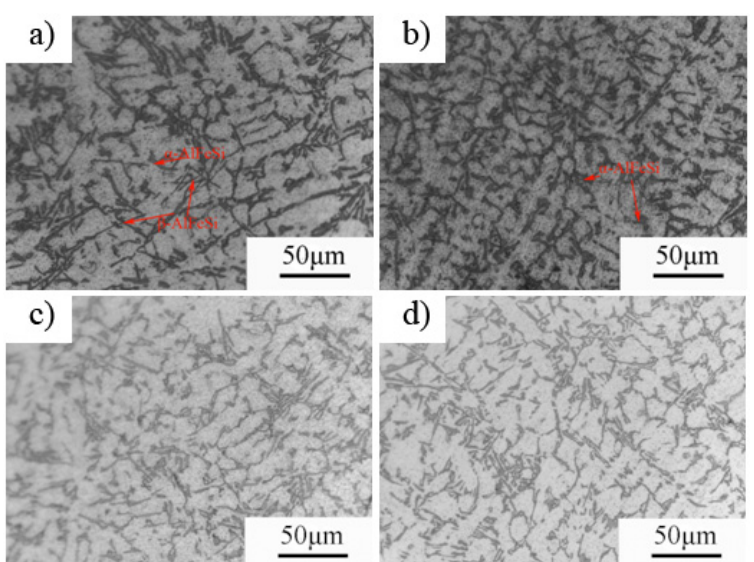

Figure 3. Microstructure of 380 alloy with different $\mathrm{K}$ addition at $10{ }^{\circ} \mathrm{C} / \mathrm{s}$

(a) 0.1 ; (b) 0.5 ; (c) 1 ; (d)2 

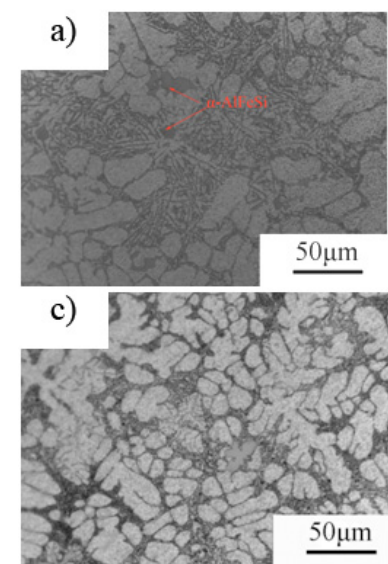

b)

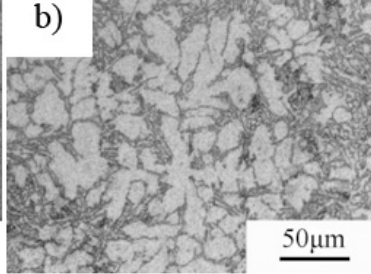

d)

Figure. 4 Microstructure of 380 alloy with different $\mathrm{K}$ addition at $20{ }^{\circ} \mathrm{C} / \mathrm{s} \quad$ (a) 0.1 ; (b) 0.5 ; (c) 1 ; (d) 2

Table 1. Chemical compositions of A380 alloy

\begin{tabular}{ccccccccc}
\hline & $\mathrm{Si}$ & $\mathrm{Fe}$ & $\mathrm{Cu}$ & $\mathrm{Mn}$ & $\mathrm{Mg}$ & $\mathrm{Ni}$ & $\mathrm{Zn}$ & $\mathrm{Al}$ \\
\hline $\begin{array}{c}\text { Specific } \\
\text { conc. (wt\%) }\end{array}$ & 9.0 & 1.0 & 3.6 & 0.4 & 0.1 & 0.3 & 0.35 & Bal. \\
\hline
\end{tabular}

Table 2. Parameters of $\alpha$-AlFeSi and $\beta$-AlFeSi morphology in A380-0.1K alloy with different cooling rates

\begin{tabular}{cccccc}
\hline $\begin{array}{c}\text { Cooling Rate } \\
\left({ }^{\circ} \mathrm{C} / \mathrm{s}\right)\end{array}$ & $\beta$-length $(\mu \mathrm{m})$ & $\beta$-width $(\mu \mathrm{m})$ & Aspect ratio & $\beta$-fraction $(\%)$ & $\alpha$-fraction $(\%)$ \\
\hline 5 & 28.71 & 1.53 & 18.77 & 1.21 & 2.43 \\
10 & 10.17 & 1.32 & 7.70 & 0.91 & 2.65 \\
20 & - & - & - & - & 3.61 \\
\hline
\end{tabular}

Table 3. Parameters of $\alpha$-AlFeSi and $\beta$-AlFeSi morphology in A380-0.5K alloy with different cooling rates

\begin{tabular}{cccccc}
\hline $\begin{array}{c}\text { Cooling Rate } \\
\left({ }^{\circ} \mathrm{C} / \mathrm{s}\right)\end{array}$ & $\beta$-length $(\mu \mathrm{m})$ & $\beta$-width $(\mu \mathrm{m})$ & Aspect ratio & $\beta$-fraction $(\%)$ & $\alpha$-fraction $(\%)$ \\
\hline 5 & 20.72 & 1.37 & 18.89 & 0.41 & 3.21 \\
10 & 18.32 & 1.47 & 12.47 & 0.23 & 3.51 \\
20 & - & - & - & - & 3.82 \\
\hline
\end{tabular}

Table 4. Parameters of $\alpha$-AlFeSi and $\beta$-AlFeSi morphology in A380-1K alloy with different cooling rates

\begin{tabular}{cccccc}
\hline $\begin{array}{c}\text { Cooling Rate } \\
\left({ }^{\circ} \mathrm{C} / \mathrm{s}\right)\end{array}$ & $\beta$-length $(\mu \mathrm{m})$ & $\beta$-width $(\mu \mathrm{m})$ & Aspect ratio & $\beta$-fraction $(\%)$ & $\alpha$-fraction $(\%)$ \\
\hline 5 & 10.83 & 0.91 & 11.90 & 0.32 & 3.31 \\
10 & - & - & - & - & 3.63 \\
20 & - & - & - & - & 3.53 \\
\hline
\end{tabular}

Table 5. Parameters of $\alpha$-AlFeSi and $\beta$-AlFeSi morphology in A380-2K alloy with different cooling rates

\begin{tabular}{cccccc}
\hline $\begin{array}{c}\text { Cooling Rate } \\
\left({ }^{\circ} \mathrm{C} / \mathrm{s}\right)\end{array}$ & $\beta$-length $(\mu \mathrm{m})$ & $\beta$-width $(\mu \mathrm{m})$ & Aspect ratio & $\beta$-fraction $(\%)$ & $\alpha$-fraction $(\%)$ \\
\hline 5 & - & - & - & - & 3.59 \\
10 & - & - & - & - & 3.64 \\
20 & - & - & - & - & 3.56 \\
\hline
\end{tabular}

Ashtari, Tezuka and Sato [5] proposed several reasons why addition of $\mathrm{K}$ can lead to a refinement of the $\beta$-AlFeSi phase and transfer of $\beta$-AlFeSi to $\alpha$-AlFeSi as follows. The addition of $\mathrm{K}$ decreases eutectic $\mathrm{Si}$ formation temperature and increases fcc $\alpha$-Al formation temperature and formation temperatures of the $\beta$-AlFeSi. It is because the increase of nucleation site. The increasing nucleation sites are possibly $\mathrm{K}_{2} \mathrm{O} . \mathrm{K}_{2} \mathrm{O}$ let the $\alpha$-AlFeSi to nucleate at a high cooling rate, while the $\beta$-AlFeSi at a low cooling rate.

From the experiment results it can be seen that most $\alpha$ compound connects with some oxidation and according to literature review, it should be $\mathrm{K}_{2} \mathrm{O}$. But Ashtari [5] suggests that $\mathrm{K}_{2} \mathrm{O}$ can be the nucleation site of the $\beta$ compound which increases the $\beta$-compound nucleation 
temperature and reduces the eutectic temperature. Because the size of $\beta$-compound is mainly controlled by the growth of the dendrite stage; in other words, it is controlled by the temperature between the nucleation temperature of $\beta$-compound and eutectic temperature. Then the size of the $\beta$-compound should be increased which is in contradiction with the experimental results. The reason for the increase is the nucleation of $\alpha$ compound on $\mathrm{K}_{2} \mathrm{O}$. From the high magnification images, it can be seen that at the center of $\alpha-\mathrm{AlFeSi}$, a point nucleate center, there exists an oxide layer of $\mathrm{K}_{2} \mathrm{O}$. It should be the nucleate center for an $\alpha$-compound.

Table 6 shows the chemical analysis of the $\mathrm{K}$ compound and the $\alpha$-AlFeSi in Fig. 5. It is possible that most of the $\mathrm{K}$ compound was removed during polishing. However, a trace of $\mathrm{K}$ and $\mathrm{O}$ remains. The chemical analysis of the $\alpha$-AlFeSi does not exhibit any amount of $\mathrm{K}$. So the $\mathrm{K}$ compounds are possibly $\mathrm{K}_{2} \mathrm{O}$.

The effectiveness of nucleation of AlFeSi phase on oxide films can be calculated by the planar disregistry $\delta$. As we discussed, it is the only way that be calculated quantitatively. For this reason, it was used as the main calculation of probable nucleation potential and also to evaluate the experimental results. The planar disregistry can be expressed as follows [6]:

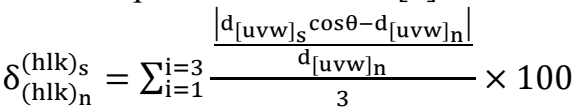

where $(\mathrm{hlk})_{\mathrm{s}}=\mathrm{a}$ low-index plane of the substrate;

$[\mathrm{uvw}]_{\mathrm{s}}=\mathrm{a}$ low-index direction in $(\mathrm{hlk})_{\mathrm{s}}$;

$(\mathrm{hlk})_{\mathrm{n}}=$ a low-index plane in the nucleated solid; $[\mathrm{uvw}]_{\mathrm{n}}=\mathrm{a}$ low-index direction in (hlk) $\mathrm{n}$;

$\mathrm{d}_{[\mathrm{uvw}]_{\mathrm{n}}}=$ an interatomic spacing along [uvw $]_{\mathrm{n}}$;

$\mathrm{d}_{[\mathrm{uvw}]_{\mathrm{s}}}=$ an interatomic spacing along $[\mathrm{uvw}]_{\mathrm{s}}$; and $\theta=$ an angle between $[\mathrm{uvw}]_{\mathrm{s}}$ and $[\mathrm{uvw}]_{\mathrm{n}}$.

Campbell [7] assumed that the electronic (bonding) contribution to the energy of the interface is favorable, if the planar disregistry is less than about 12 pct.

Table 7 show calculated results for planar disregistry in our study. A quick review of the $\mathrm{K}_{2} \mathrm{O}$ is good nucleation substrates of $\alpha-\mathrm{AlFeSi}$. So this can explain why $\mathrm{K}$ can modify $\beta$-AlFeSi.

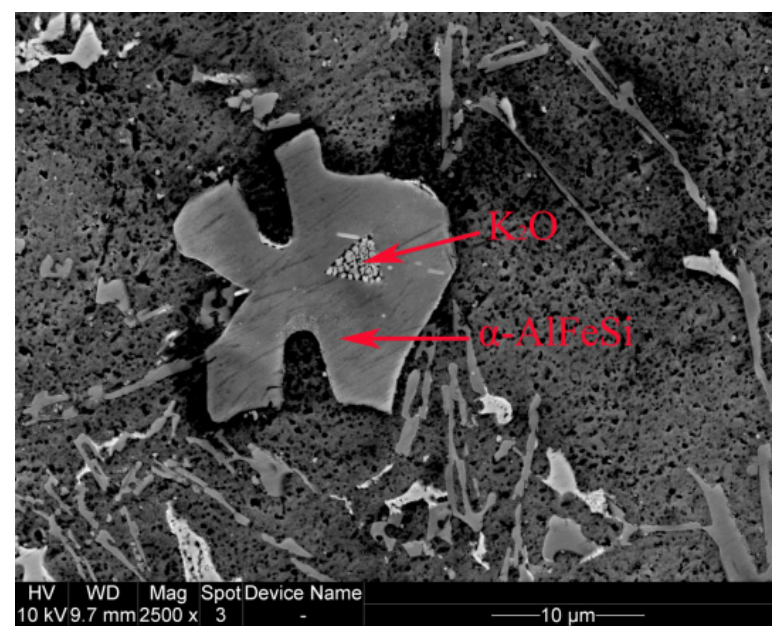

(a)

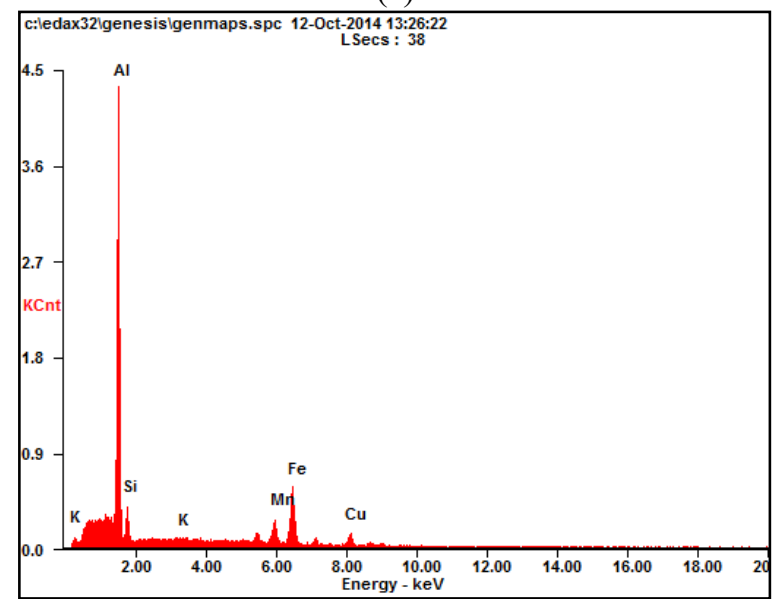

(b) 


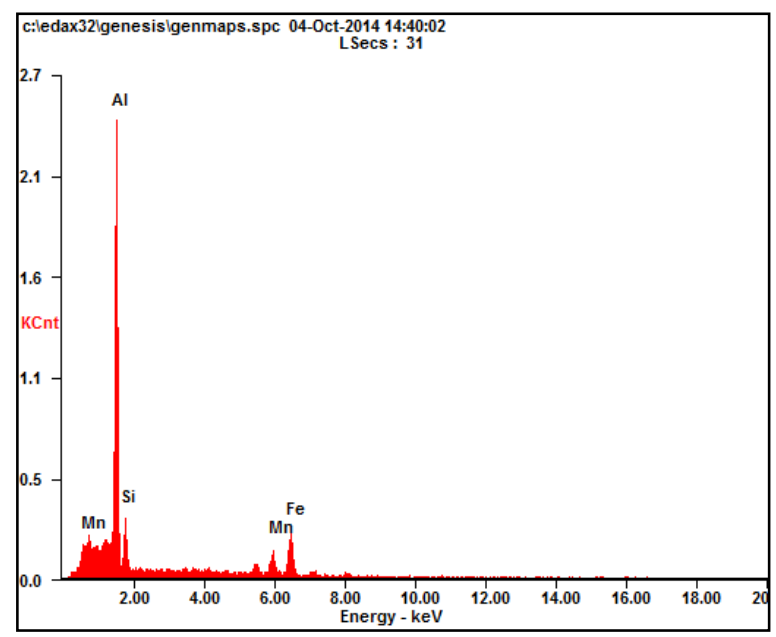

(c)

Figure. 5 Relation of $\mathrm{K}_{2} \mathrm{O}$ and $\alpha-\mathrm{AlFeSi}$

(a) SEM images showing nucleation of $\alpha$-AlFeSi from K2O; (b) EDS of $\mathrm{K} 2 \mathrm{O}$ zone; (c)EDS of $\alpha$-AlFeSi

Table 6. Chemical composition of the phases indicated in Fig. 5 (at.\%)

\begin{tabular}{ccccccc}
\hline Phase & $\mathrm{Al}$ & $\mathrm{Si}$ & $\mathrm{Mn}$ & $\mathrm{Fe}$ & $\mathrm{K}$ & $\mathrm{O}$ \\
\hline $\mathrm{K}_{2} \mathrm{O}$ zone & 72.29 & 9.06 & 1.58 & 4.45 & 0.29 & 12.32 \\
$\alpha$-AlFeSi & 69.90 & 13.87 & 5.32 & 10.90 & - & - \\
\hline
\end{tabular}

Table 7. Planar disregistries between $\mathrm{K}_{2} \mathrm{O}$ and $\alpha$-AlFeSi

\begin{tabular}{|c|c|c|c|c|c|c|}
\hline Match Planes & {$[\mathrm{hkl}] \mathrm{s}$} & {$[\mathrm{hkl}] \mathrm{n}$} & $\mathrm{d}[\mathrm{hkl}] \mathrm{s}(\mathrm{nm})$ & $\mathrm{d}[\mathrm{hkl}] \mathrm{n}(\mathrm{nm})$ & $\theta$ & $\delta(\mathrm{Pct})$ \\
\hline \multirow[t]{3}{*}{$(001) \mathrm{s} / /(001) \mathrm{n}$} & {$[100]$} & {$[100]$} & 0.7859 & 1.265 & $0 \mathrm{deg}$ & 4.15 \\
\hline & [110] & [110] & 1.11143 & 1.78898 & $0 \mathrm{deg}$ & \\
\hline & {$[010]$} & [010] & 0.7859 & 1.265 & $0 \mathrm{deg}$ & \\
\hline \multirow[t]{3}{*}{$(110) \mathrm{s} / /(110) \mathrm{n}$} & [001] & [001] & 0.7859 & 1.265 & $0 \mathrm{deg}$ & 4.15 \\
\hline & {$[\overline{1} 11]$} & {$[\overline{1} 11]$} & 1.361219 & 2.191044 & $0 \mathrm{deg}$ & \\
\hline & {$[\overline{1} 10]$} & {$[\overline{1} 10]$} & 1.11143 & 1.78898 & $0 \mathrm{deg}$ & \\
\hline \multirow[t]{3}{*}{$(111) \mathrm{s} / /(111) \mathrm{n}$} & {$[\overline{1} \overline{1} 2]$} & {$[\overline{1} \overline{1} 2]$} & 1.925054 & 3.098605 & 0 deg & 4.44 \\
\hline & {$[\overline{3} 12]$} & {$[\overline{3} 12]$} & 2.940569 & 4.733197 & $7.68 \mathrm{deg}$ & \\
\hline & {$[\overline{1} 10]$} & {$[\overline{1} 10]$} & 1.11143 & 1.78898 & 0 deg & \\
\hline
\end{tabular}

It can also been seen that high cooling rate can effectively confine the formation of $\beta$-AlFeSi. Here $\beta$ AlFeSi is the primary stable phase and increasing cooling rate will suppress the formation of $\beta$-AlFeSi phase. Under this situation, from the simulation results and experimental results, in addition to some reference, $\beta$ $\mathrm{AlFeSi}$ is the predominant phase compared to $\alpha$-AlFeSi. [8] The relation of cooling rates and AlFeSi phase fraction is similar to that of the AlFeSi ternary alloys. Without the addition of $\mathrm{Mn}, \beta-\mathrm{AlFeSi}$ is the stable phase and $\alpha-\mathrm{AlFeSi}$ phase is the metastable phase. $\beta$-AlFeSi will be the primary phase and $\alpha-\mathrm{AlFeSi}$ will form in the main eutectic stage. The higher cooling rates reduce the starting formation temperature of the $\beta$-AlFeSi phase. With decreasing starting temperature of the $\beta$-AlFeSi phase, of the growth time of the $\beta$-AlFeSi phase is reduced and therefore the length and volume fraction of this phase decrease until the $\beta$-AlFeSi phase start temperature merges with the silicon eutectic temperature. At the end of the formation of the silicon eutectic stage, the remaining liquid, depleted in silicon, favors crystallization of the $\alpha$-AlFeSi phase.

The refinement of eutectic $\mathrm{Si}$ by $\mathrm{K}$ addition is observed. P. Ashtari [5] claimed that $\mathrm{K}$ incorporates into the $\mathrm{Si}$, which is consistent of the model of $\mathrm{Lu}$ and Hellawell. They suggested that adsorption of the modifier element atoms on the $\mathrm{Si}$ liquid interface could be responsible for affecting the growth of $\mathrm{Si}$, increasing the twin density in the eutectic Si. This model is called impurity induced twinning (IIT). The results in our research confirm that.

\section{Conclusion}

In this paper, the influence of $\mathrm{K}$ addition on the modification of the AlFeSi intermetallics has been investigated for A380 alloys containing 1 wt.\% Fe. The conclusions are summarized as follows:

(1) The addition of $\mathrm{K}$ is very effective in modifying the platelet $\beta$-AlFeSi compound to Chinese script/ spherical $\alpha$-AlFeSi compound during a high cooling rate. 
The reasons lies in the combination of modification and high cooling rates

(2)The mechanism of refinement is that $\mathrm{K}$ can be the nucleate center of $\alpha$-AlFeSi

(3) $\mathrm{K}$ simultaneously modifies the eutectic $\mathrm{Si}$ and changes the morphology from flake to lamellar.

(4)The addition of K should be carefully controlled to avoid the coarsening of the eutectic Si and the introduce oxide layer. The optimum $\mathrm{K}$ addition is found to be about 2.0 wt. $\% \mathrm{~K}$ addition.

\section{Acknowledgments}

This work was supported by Young Innovative Talents Project of General Colleges and Universities in Guangdong Province (2019GKQNCX127) and the Research Funding of Shenzhen Polytechnic (6019310005K)

\section{References}

1. Lu L and Dahle AK (2011) Iron-rich intermetallic phases and their role in casting defect formation in hypoeutectic Al-Si alloys, Metall Mater Trans A, 36: 819-835.

2. Dinnis CM, Taylor JA and Dahle AK (2005) As-cast morphology of ironintermetallics in Al-Si foundry alloys, Scripta Mater, 53: 955-958.

3. Zhang L, Gao J, Damoha L, and Robertson DG (2012) Removal of Iron From Aluminum: A Review, Miner Process Extr M, 39: 99-157.

4. Samuel AM and Samuel FH (1995) Effect of alloying elements and dendrite arm spacing on the microstructure and hardness of an Al-Si-Cu-Mg-MgFe-Mn (380), J Mater Sci, 301: 1698-1708.

5. Ashtari P, Hiroyasu $\mathrm{T}$ and Tatsuo S (2005) Modification of Fe-containing intermetallic compounds by $\mathrm{K}$ addition to Fe-rich AA319 aluminum alloys, Scripta Mater, 53: 937-942.

6. Cao, X and Campbell J (2004) Effect of Sr on primary $\alpha$-Fe phase in liquid $\mathrm{Al}-11.5 \mathrm{Si}-0.4 \mathrm{Mg}$ cast alloy, Mater Sci Tech-Lond, 20: 514-520.

7. Campbell J (1991) Casting. Butterworth-Heinemann, Oxford

8. Narayanan LA, Samuel FH and Gruzleski JE (1994). Crystallization behavior of iron-containing intermetallic compounds in 319 aluminum-alloy, Metall Mater Trans A, 25: 1761-1773. 